\title{
Emergency Preparedness within the Hotel Industry: A Case Study of Wuhan City, China
}

\author{
Lihui $\mathrm{Wu}^{1,2}$, Huali $\mathrm{Xia}^{1 *}$, Sarina $\mathrm{Bao}^{3}$ \\ ${ }^{1}$ School of Management, Hubei University of Education, Wuhan 430205, Hubei, China \\ ${ }^{2}$ Institute of Supply Chain Operation and Service Innovation, Hubei University of Education, Wuhan 430205, Hubei, China \\ ${ }^{3}$ Department of Environmental Science and Policy, University of California, Davis, CA 95616, USA
}

Corresponding Author Email: xiahuali@ hue.edu.cn

https://doi.org/10.18280/ijsse.110105

Received: 20 April 2020

Accepted: 3 January 2021

\section{Keywords:}

hotel industry, emergency preparedness, risks, "five-star" hotels, Wuhan city

\begin{abstract}
The hospitality industry is one of the most vulnerable to emergency events and can be highly affected by various hazards. Within the hospitality industry, hotels are faced with multi-crises and disasters. Emergency preparedness is one of the most efficient ways to deal with emergencies and increase the resilience of the businesses, especially in highrisk areas. This research aims to identify the main risks that may threaten hotels and investigate the state of emergency preparedness of "five-star" hotels in Wuhan city, China, by conducting interviews among general manager and sending questionnaires to safety and security managers in the hotel sectors. Findings show that Wuhan's hotels are exposed to a wide range of risks, and all of the respondent five-star hotels have plans or frameworks prepared for crises and disasters. Results indicate that there is an overall high level of preparedness for crises and disasters in five-star hotels in Wuhan, China. Findings also reveal that many of the challenges facing hoteliers are connected to emergency communication and tourist-oriented disaster preparedness planning. On the basis of the results, implications are discussed. It is hoped that this paper will shed light on emergency preparedness for hotel industry.
\end{abstract}

\section{INTRODUCTION}

We live in an increasingly disaster prone world [1] and the hotel industry is highly susceptible to a wide range of hazards $[2,3]$. Tourism industry is vulnerable to a series of crisis and disasters as it is a comprehensive industry and relies on many components and various types of individual businesses. Safety and security are essential conditions for tourism development and thus the fundamental determinants for its growth [4]. Hotels that are well prepared for emergencies can not only protect guests and their staff, but also avoid or mitigate financial and reputational losses when disaster or crisis happens.

Tourism industry has been largely affected by crises and disasters in recent years, including man-made disasters and natural hazards $[2,3,5]$. Within the tourism industry, the hotel sector's vulnerabilities are multi-faceted [6]. Emergency preparedness is an efficient way to help mitigate damages or losses caused by threats. However, the existing literatures mainly focus on emphasizing the importance of emergency management and response strategies from the perspective of the central or local governments, communities, households, individuals, etc., and there is relative less literature regarding emergency management preparedness in hospitality industry in general [7] and even less discuss emergency preparedness for hotel sectors. Many researchers [1,8-10] argued that the current literatures regarding tourism industry mainly focused on emergency response and recovery, paying less attention to preventive measures and preparedness capacities. Faulkner [1] indicated that due to the ignorance of the importance of disaster planning and preparedness, few tourism sectors have properly disaster management plans in place to cope with hazards. Therefore, this article will explore the major risks that most likely threaten hotels and investigate actual emergency preparedness level adopted by hotels to manage crises and disasters.

Wuhan city, as the capital of Hubei province, is the largest city in Central China with an area of 8,494 square kilometers and has long been an economic, industrial and transportation hub for both the region and country. According to the Wuhan Municipal Bureau of Culture and Tourism, international tourists visiting Wuhan grew by $10.57 \%$ to a total 2.77 million and domestic tourists reached 0.285 billion with the growth rate of $10.88 \%$ in 2018 . Though tourism industry has been developing rapidly in Wuhan for the last 20 years and achieved great success, tourism businesses including hotels were negatively affected by many crises and disasters, including September 11 terrorist attack, Severe Acute Respiratory Syndromes (SARS), global financial crisis, drought-flood disasters. Therefore, here Wuhan city was chosen as a case area to examine the major risks for hotels and investigate their emergency preparedness level.

\section{LITERATURE REVIEW}

\subsection{Risks and tourism industry}

Faulkner [1] noted that we live an increasing number of disasters and crises affect tourism industry. There is a wide agreement among the authors regarding the negative and significant influences of disaster and crisis on tourism industry 


\section{$[2,11]$.}

Since the September 11th terrorist attack in 2001, the impacts of crisis events and disasters on tourism industry have attracted increasing concerns. Goodrich [12], Baker [13], and Sloboda [14] discussed the impacts of terrorist activities on tourism industry and argued that terrorist attacks were great challenges for tourism sectors. Goodrich [12] explored the impacts of the September 11 terrorist attacks on the travel and tourism industry in the USA and found that U.S. hotel occupancy dropped by half with at least US\$2 billion losses after September 11. Chien and Law [8], Henderson and $\mathrm{Ng}$ [15], Kim et al. [16], Pine and McKercher [17], and discussed the negative impacts of epidemic outbreaks including the outbreaks of SARS and the food and mouth disease on tourism industry, mainly on hotels, and pointed out the importance to take effective measures to mitigate losses. Due to the impact of SARS outbreak in 2003, the occupancy rates of many hotels in Hong Kong fell to 10\% or lower in March and April 2003, normally with an average occupancy rate of about $86 \%$ [8].

Natural disasters have also been concerned in tourism management. Mazzocchi and Montini [18], Yang et al. [19] and Orchiston [20] discussed the negative influences of earthquakes on tourism industry. Huang and Min [21] analyzed the recovering status of inbound tourism demand in Taiwan aftermath of September 21 Earthquake and found that after 11 months Taiwan had not yet fully recovered from sharply reduced inbound arrivals due to the earthquake. $\mathrm{Wu}$ and Hayashi [22] quantitatively analyzed the impacts of several types of disasters on international demand in Japan and the results revealed that earthquakes most significantly and seriously affected the tourism industry. Sharpley [23] and Ichinosawa [24] explored the influences of tsunami on tourism industry. In the aftermath of the 2004 Indian Ocean tsunami, there was a dramatic decline of $85 \%$ in international tourists and hotel occupancy rates fell to $10 \%$ in Phuket, Thailand [25]. Ghaderi et al. [26] investigated the effects of the Thai Floods of 2011 on tourism industry.

The hotel sector is one of the most vulnerable businesses to emergency events and has be affected by external and internal hazards [15, 27]. Beside external crisis and disasters mentioned above, the sector has also been susceptible to many different kinds of hazards including falls, burns, cuts, theft, slips, fire and other related security events, which might cause death or injures [27, 28], thus affecting the reputation of the sectors or even worse the whole tourism destination. Crimerelated incidents, which can be in the form of larceny, theft, robbery, rape, murder, piracy and kidnapping, triggered some form of negative impact on the tourism industry [29]. There is still a lack of research on the development of preventive and efficient countermeasures and crisis and disaster management in hospitality industry [1, 3, 9]. Meanwhile, dealing with emergencies is a complicated task in the hotel sector as the numerous staff and guests need to be accommodated [15].

\subsection{Determinants of tourism emergency preparedness}

Haddow et al. [30] defined emergency management as dealing with hazards timely and taking action to avoid hazards. Ritchie [2] noted that the negative effects of crisis and disasters cannot be stopped, but they can be mitigated and prevented by developing disaster or crisis planning and taking preparedness countermeasures. Increasing studies have investigated disaster preparedness and discussed factors related to disaster preparedness.
Dalhamer and D'Sousa [31] suggested the size of the business is the strongest predictor of business disaster preparedness and smaller businesses usually have lower level of preparedness due to the lack of staff and time to engage in emergency preparedness activities. Caponigro [32] noted that whether a business has an emergency plan mainly depends on its size and financial factors, so large businesses are more likely to have emergency plans than smaller ones. In addition to limited resources, Caponigro [32] suggested that small organizations do not attach importance to crisis planning as they believe crisis events will not affect their business or they can manage their business well without a disaster or crisis plan. Hystad and Keller [9] also confirmed that larger businesses are more likely to plan for disasters than smaller businesses from the perspective of the capacity and human resource available. Besides business size, Dalhamer and D'Sousa [31] also mentioned ownership and previous disaster experience as significant determinants of business disaster preparedness. This is in accordance with previous research that the organizations having ever experienced disasters or crisis events before are more likely to develop their own emergency plans, because they suffer from the previous hazards and learn from the events [33].

In addition to the predictors mentioned above, managers' risk perception, threat knowledge and motivation are also frequently discussed as key predictors affecting business disaster preparedness [34]. Drabek [34] revealed tourist managers' risk perception has a strong correlation with the extent of disaster planning. Risk perception of tourist managers ensure the implementation of appropriate levels of planning, mitigation and preparedness [35]. Webb et al. [36] argued business preparedness is inevitably influenced by the managers' risk perception and motivation to prepare for emergencies. Managers should be aware of the importance of emergency planning, full detailed information about their hotels, and safety and security procedures adopted in the case of emergency events [27].

\subsection{Emergency management preparedness}

Prevention, Preparedness, Response and Recovery (or PPRR) cycle is one of the fundamental concepts of emergency management process and describes the events that occur before, during and after an emergency event [37]. Emergency management practice has been widely discussed and generally divided into three stages, the pre-event stage, event stage and post-event stage $[3,38,39]$. In the pre-event stage, proactive and prevention measures such early warning systems, disaster planning are required to prevent or mitigate hazard impact [38]. When crisis or disaster occurs, it is hoped to provide an immediate and effective response to the event and mitigate the impact of the event [37]. During post-event stage, actions are taken to recover from the damage including rehabilitation and post-disaster reconstruction [3]. In most existing literature, preparedness is generally regarded as an important stage of emergency management process or key activities in pre-event stage. However, currently researchers argue preparedness should be incorporated in the whole process of emergency management. According to Sutton and Tierney [40], emergency preparedness not only consists of measures to enhance life safety when a disaster occurs, also includes actions designed to enhance the ability to undertake emergency actions in order to protect property and contain disaster damage and disruption, as well as the ability to engage 
in post-disaster restoration and early recovery activities. Therefore, the activities of emergency management preparedness have been identified with developing planning processes to ensure readiness, formulating disaster plans, allocating resources necessary for effective response and developing skills and competencies to ensure effective performance of disaster-related tasks [40, 41]. Among the approaches, great importance has been attached to emergency planning, early warning and community involvement [42]. Emergency planning and preparedness for crisis are the most significant components while dealing with disasters [27]. Fink and Association [43] suggested efficient planning has an important role in emergency management and planning for emergencies is critical to control the existing event. A survey of tourism business operators revealed generally poor levels of perceived preparedness and actual planning for a future earthquake disaster, particularly amongst micro-sized businesses [20]. The literature on emergency management has highlighted the importance of being prepared, developing planning, emergency response and recovery measures. However, there are relatively fewer literatures on exploring how tourism businesses prepare for emergency events.

\section{METHODOLOGY}

Interviews and questionnaires were used to collect data pertaining to emergency preparedness of five-star luxury hotels in Wuhan, China. The questionnaire survey was followed by semi-structured interviews with five general managers from five hotels of the main commercial districts (Wuchang, Hankou and Hanyang). Interviews were undertaken in order to provide insight of the managers' perception of disaster and crisis management in Wuhan's hotels and invite them to check our questionnaire in July 2019. The interview topic focused on emergency preparedness and specific content referred to "What do you think of emergency management in hotel industry?", "Does your hotel have disaster/crisis planning?", "Does your hotel have disaster prevention drills?", "What do you think how hotel industry prepare for emergency events?" etc.

With the aim to evaluate the state of emergency preparedness of hotels, our questionnaire is divided into four sections, general information, pre-event preparedness issues, preparedness practice when emergency event occurs and postevent preparedness. The questionnaire includes 36 closeended questions that were developed to explore perception of major risks facing hotels in Wuhan and assess preparedness situation of the hotels.

Considering business size and financial factors, we focus on five-star hotels, which are more likely to prepare for emergency events. The sample includes 11 hotels which are all five-star hotels in Wuhan, China. As safety and security departments are mainly responsible for the planning, preparedness, and implementation of emergency management activities in large-scale hotels, the questionnaires are all sent to the safety and security department of each hotel. Questionnaires were sent via email to the respective safety and security managers of the hotels and they were assured that their responses would be kept strictly confidential and be used exclusively for research purposes. To ensure participants anonymity, the respondents were required to return the questionnaires through email to a certain email address of the Department of Hospitality and Tourism Management, School of Management, Hubei University of Education. To improve response rate, before sending questionnaires, we called the managers of the hotels to introduce the objectives and contents of the survey and asked for the help to complete the questionnaires. One week later, follow-up calls were made to the directors as a reminder to send the completed questionnaires back. Lastly, we received 11 valid questionnaires resulting in a $100 \%$ response rate. Statistical analysis was conducted using SPSS 17.0 statistical software.

\section{ANALYSIS AND RESULTS}

\subsection{General information}

First the respondents were requested to indicate their positions. The results show the respondents include $36 \%$ safety and security managers and $64 \%$ safety and security deputy managers. $45.5 \%$ hotels had been running for over 10 years. $54.5 \%$ of the hotels were built up in recent 10 years. All 11 hotels have more than 20 floors and offered over 300 guest rooms. Eighty-two percent of the hotels have more than 300 employees. According to the respondents, 100 percent of the hotels have ever experienced disasters or crises in the last ten years.

\subsection{Risk perception}

In the questionnaire, the first question regarding risk perception is "What do you think of the main risks facing hotels in Wuhan city?" We provided 13 choices of risks including internal and external factors (fire disasters, typhoon, earthquake, drought, infectious diseases, flood, security events, food poisoning, fault caused by attendants when providing service, safety events in hotels, terrorist attacks, financial crisis and international tension) that might influence hotel business negatively, and respondents were required to identify and tick the top 5 risks that are much more likely to threaten the hotels in Wuhan. The answers are shown in Table 1. The findings reveal that fire disaster is the major risk that most probably threatens hotels as all respondents ticked the choice. $72.7 \%$ of the respondents argue that fault caused by attendants, safety events and security events are the main risks facing hotels in Wuhan, followed by food poisoning $(63.3 \%)$, infectious diseases $(54.5 \%)$, flood $(18.2 \%)$, terrorist attacks $(18.2 \%)$, financial crisis $(18.2 \%)$ and typhoon $(9.1 \%)$. The results indicate that the hotels are vulnerable to a series of risks and highly susceptible to disasters and crises, though the respondents do not think earthquake, drought international tension would affect the business.

On the basis of literature review, this study provided 6 choices about probable impacts of emergency events on hotel industry, including lifeline functional failure, business interruption or bankruptcy, casualties of guests or employees, guests decrease, reputation damage and loss of confidence by investors and the staff. Respondents were requested to identify the main impacts by the means of multiple-choice questions, the question "what are the major impacts caused by emergency events?". Table 2 shows that reputation damage is a major concern of all hotels when emergency events occur. The result is accordance with the facts that word-of-mouth is especially important for tourism industry because of the characteristics of intangibility that the products are difficult to evaluate prior to their consumption in the tourism industry [44]. Meanwhile, 
$90 \%$ of the respondents are worried that the emergency events would cause lifeline functional failure and business interruption or bankrupt. Other choices are also regarded as main concerns (shown in Table 2).

Table 1. Major risks facing hotels in Wuhan city

\begin{tabular}{ccc}
\hline Risks & Frequency & \% of respondents \\
\hline Fire disasters & 11 & 100 \\
Fault caused by attendants when providing service & 8 & 72.7 \\
Safety events due to negligence in hotels & 8 & 72.7 \\
Security events & 8 & 72.7 \\
Food poisoning & 7 & 63.6 \\
Fnfectious diseases such as the SARS outbreak in 2003 & 6 & 54.5 \\
Flood & 2 & 18.2 \\
Terrorist attacks such as the September 11 terrorist attacks in 2001 & 2 & 18.2 \\
Financial crisis & 2 & 18.2 \\
Typhoon & 1 & 9.1 \\
Earthquake & 0 & 0.0 \\
Drought & 0 & 0.0 \\
International tension & 0 & 0.0 \\
\hline
\end{tabular}

Table 2. Major impacts caused by emergency events

\begin{tabular}{ccc}
\hline Major impacts caused by the risks & Frequency & \% of respondents \\
\hline Reputation damage & 11 & 100 \\
Lifeline functional failure & 10 & 90.9 \\
Business interruption or bankruptcy & 10 & 90.9 \\
Casualties of guests or employees & 9 & 81.8 \\
Guests decrease & 9 & 81.8 \\
Investors and staff will lose confidence in their hotels. & 7 & 63.6 \\
\hline
\end{tabular}

\subsection{Emergency management preparedness}

Table 3. Emergency preparedness strategies/actions

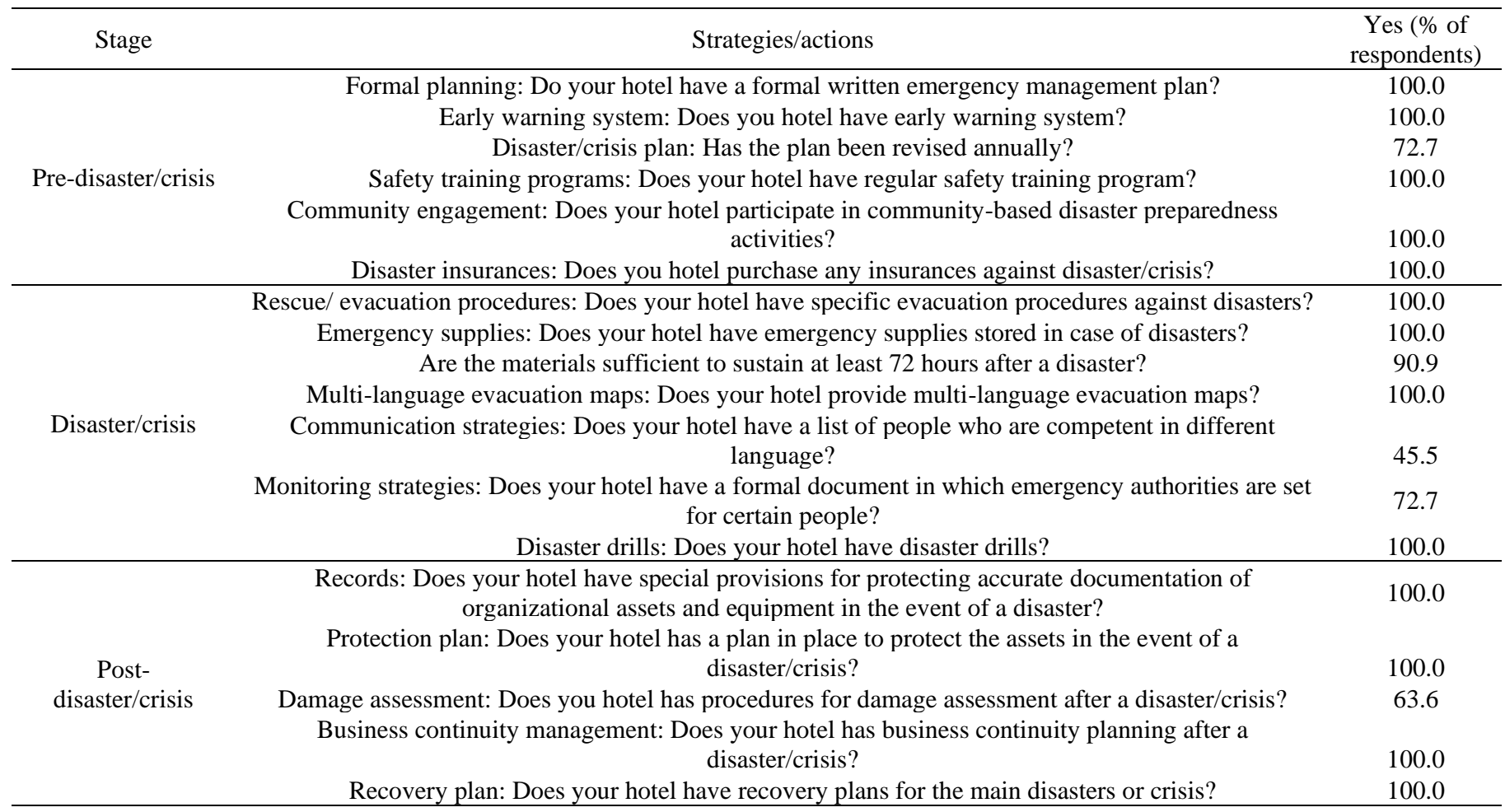

The third portion of the questionnaire listed strategies or actions in different emergency management stages on the basis of a review of literature. Respondents were requested to identify the preparedness measures adopted in their businesses for emergency management by the question "Does your hotel have taken the following Emergency preparedness strategies/actions?" The choices were provided on the basis of different emergency event stages, pre-disaster/crisis, disaster/crisis and post-disaster/crisis. The items and results are shown in Table 3 .

The results show that in pre-disaster/crisis preparedness stage, all of the participating hotels have formal written emergency plans, their own early warning system, safety training programs. Furthermore, they have engaged in 
community-based emergency preparedness activities and brought insurances against disaster or crisis. Moreover, 72.7\% hotels revise their disaster or crisis plan annually.

With regard to emergency preparedness in disaster/crisis response phase, all of the participating businesses have their own rescue or evacuation procedures, emergency supplies, multi-language evacuation maps and organized disaster drills. Regarding the issue of emergency supply, the majority of the hotels $(90.9 \%)$ have sufficient emergency supplies to sustain at least 72 hours. $72.7 \%$ of the hotels have formal document appointing and empowering certain staff temporary positions to handle emergencies. However, less than half $(45.5 \%)$ of the respondents indicate that they have a list of staff who can speak different languages.

In post-disaster/crisis recovery stage, all of respondents indicate that they have special provisions for protecting documentation, protection plans for the assets and recovery plans. The findings also show that more than half (63.6\%) have the procedures to assess damage after a disaster or crisis.

\section{CONCLUSIONS}

With the increasing number of disasters and crises, there is an urgent need in tourism sectors to make preparedness for emergency events as tourism industry is one of the most susceptible industries to emergencies. This study was designed to fill the gap in the literature on the emergency management preparedness of hotels in Wuhan city, China, contributing to the understanding of the major risks facing the hotels and the state of the emergency preparedness level.

Overall, using the previous findings $[3,4,20,45]$ as benchmarks, the results of the current study reveal that hotels in Wuhan are well prepared for disasters and crises that may threaten the businesses, though the businesses face many different types of disasters and crises, including fire disaster, fault caused by attendants, safety events, security events and food poisoning. In pre-disaster/crisis phase, all of the respondents indicate that they have formal emergency plan and more than $70 \%$ of the businesses revise the plan annually. All of the businesses engage in community-based disaster emergency preparedness activities and purchase insurance against disasters or crises. During disaster/crisis stage, all of the respondents denote that their businesses have made sufficient preparedness of emergency supplies and organized disaster drills. However, there still remains considerable room for improvement in emergency preparedness for foreigners who may not be able to follow the local language and are not familiar with the facilities and environment in and around the hotels. In post-disaster/crisis phase, all of the respondents have their own protection strategies for documentation and assets, business continuity management plan and recovery plan. $63.6 \%$ of the hotels have procedures to assess damage after a disaster or crisis.

Our results provide evidence for understanding the main risks facing hotels in Wuhan and the high level of emergency management preparedness of the five-star hotels. While the current research investigated whether or not hotels get well prepared for emergency events in different stages, this study just focused on five-star hotels other than all types of hotels. This research is considered as the first step to explore emergency management preparedness of hotels. In future research, samples would be extended to other types of hotels in order to make a better understanding of emergency management preparedness level and another noteworthy focus would be the detailed issues of emergency management in different phases for certain crises or disasters such as the Wuhan Coronavirus.

\section{ACKNOWLEDGMENT}

This work was supported by the Office of Discipline Construction, Hubei University of Education, and the Starting Research Fund from Hubei University of Education (2018). We thank continuous supports from the five-star hotels in Wuhan, China.

\section{REFERENCES}

[1] Faulkner, B. (2001). Towards a framework for tourism disaster management. Tourism Management, 22(2): 135147. https://doi.org/10.1016/S0261-5177(00)00048-0

[2] Ritchie, B.W. (2004). Chaos, crises and disasters: A strategic approach to crisis management in the tourism industry. Tourism Management, 25(6): 669-683. https://doi.org/10.1016/j.tourman.2003.09.004

[3] Sawalha, I.H.S., Jraisat, L.E., Al-Qudah, K.A. (2013). Crisis and disaster management in Jordanian hotels: Practices and cultural considerations. Disaster Prevention and Management: An International Journal, 22(3): 210-228. https://doi.org/10.1108/dpm-09-20120101

[4] Wu, L., Haruo, H., Dun, W. (2019). Tourism sector preparedness in zones with a high seismic risk: A case study of the capital region of Japan. International Journal of Safety and Security Engineering, 9(2): 166-181. https://doi.org/10.2495/SAFE-V9-N2-166-181

[5] Pennington-Gray, L., Thapa, B., Kaplanidou, K., Cahyanto, I., McLaughlin, E. (2011). Crisis planning and preparedness in the United States tourism industry. Cornell Hospitality Quarterly, 52(3): 312-320. https://doi.org/10.1177/1938965511410866

[6] Brown, N.A., Rovins, J.E., Feldmann-Jensen, S., Orchiston, C., Johnston, D. (2017). Exploring disaster resilience within the hotel sector: A systematic review of literature. International Journal of Disaster Risk Reduction, 22: 362-370. https://doi.org/10.1016/j.ijdrr.2017.02.005

[7] Israeli, A.A., Reichel, A. (2003). Hospitality crisis management practices: The Israeli case. International Journal of Hospitality Management, 22(4): 353-372. https://doi.org/10.1016/s0278-4319(03)00070-7

[8] Chien, G.C., Law, R. (2003). The impact of the severe Acute respiratory syndrome on hotels: A case study of Hong Kong. International Journal of Hospitality Management, 22(3): 327-332. https://doi.org/10.1016/s0278-4319(03)00041-0

[9] Hystad, P.W., Keller, P.C. (2008). Towards a destination tourism disaster management framework: Long-term lessons from a forest fire disaster. Tourism Management, 29(1): 151-162. https://doi.org/10.1016/j.tourman.2007.02.017

[10] McCool, B. (2012). The need to be prepared: Disaster management in the hospitality industry. J Bus Hotel Manage, 1(2): 2. https://doi.org/10.4172/23249129.1000101 
[11] Pforr, C. (2006). Tourism in post-crisis is tourism in precrisis: A review of the literature on crisis management in tourism. Working Paper 2006-1, Curtin University of Technology, School of Management.

[12] Goodrich, J.N. (2002). September 11, 2001 attack on America: A record of the immediate impacts and reactions in the USA travel and tourism industry. Tourism Management, 23(6): 573-580. https://doi.org/10.1016/S0261-5177(02)00029-8

[13] Baker, D.M.A. (2014). The effects of terrorism on the travel and tourism industry. International Journal of Religious Tourism and Pilgrimage, 2(1): 9. https://doi.org/10.21427/D7VX3D

[14] Sloboda, B.W. (2003). Assessing the effects of terrorism on tourism by use of time series methods. Tourism Economics, $9(2)$ : 179-190. https://doi.org/10.5367/000000003101298349

[15] Henderson, J.C., Ng, A. (2004). Responding to crisis: Severe acute respiratory syndrome (SARS) and hotels in Singapore. International Journal of Tourism Research, 6(6): 411-419. https://doi.org/10.1002/jtr.505

[16] Kim, S.S., Chun, H., Lee, H. (2005). The effects of SARS on the Korean hotel industry and measures to overcome the crisis: A case study of six Korean five-star hotels. Asia Pacific Journal of Tourism Research, 10(4): 369377. https://doi.org/10.1080/10941660500363694

[17] Pine, R., McKercher, B. (2004). The impact of SARS on Hong Kong's tourism industry. International Journal of Contemporary Hospitality Management, 16(2): 139-143. https://doi.org/10.1108/09596110410520034

[18] Mazzocchi, M., Montini, A. (2001). Earthquake effects on tourism in central Italy. Annals of Tourism Research, 28(4): 1031-1046. https://doi.org/10.1016/S01607383(01)00008-1

[19] Yang, W., Chen, G., Wang, D. (2008). Impact of the Wenchuan earthquake on tourism in Sichuan, China. Journal of Mountain Science, 5(3): 194-208. https://doi.org/CNKI:SUN:SDKB.0.2008-03-003

[20] Orchiston, C. (2013). Tourism business preparedness, resilience and disaster planning in a region of high seismic risk: The case of the Southern Alps, New Zealand. Current Issues in Tourism, 16(5): 477-494. https://doi.org/10.1080/13683500.2012.741115

[21] Huang, J.H., Min, J.C. (2002). Earthquake devastation and recovery in tourism: The Taiwan case. Tourism Management, 23(2): 145-154. https://doi.org/10.1016/S0261-5177(01)00051-6

[22] Wu, L., Hayashi, H. (2014). The impact of disasters on Japan's inbound tourism demand. Journal of Disaster Research, 9(sp): 699-708. https://doi.org/10.20965/jdr.2014.p0699

[23] Sharpley, R. (2005). The tsunami and tourism: A comment. Current issues in Tourism, 8(4): 344-349. https://doi.org/10.1080/13683500508668222

[24] Ichinosawa, J. (2006). Reputational disaster in Phuket: the secondary impact of the tsunami on inbound tourism. Disaster Prevention and Management: An International Journal, 15(1): 111-123. https://doi.org/10.1108/09653560610654275

[25] Henderson, J.C. (2007). Corporate social responsibility and tourism: Hotel companies in Phuket, Thailand, after the Indian Ocean tsunami. International Journal of Hospitality Management, 26(1): 228-239. https://doi.org/10.1016/j.ijhm.2006.02.001
[26] Ghaderi, Z., Mat Som, A.P., Henderson, J.C. (2015). When disaster strikes: The Thai floods of 2011 and tourism industry response and resilience. Asia Pacific Journal of Tourism Research, 20(4): 399-415. https://doi.org/10.1080/10941665.2014.889726

[27] AlBattat, A.R., Mat Som, A.P. (2013). Emergency preparedness for disasters and crises in the hotel industry. Sage Open, 3(3): 1-10. https://doi.org/10.1177/2158244013505604

[28] Enz, C.A., Taylor, M.S. (2002). The safety and security of US hotels a post-September-11 report. Cornell Hotel and Restaurant Administration Quarterly, 43(5): 119-136. https://doi.org/10.1177/0010880402435011

[29] Mansfeld, Y., Pizam, A. (2006). Tourism, Security and Safety. Routledge.

[30] Haddow, G., Bullock, J., Coppola, D.P. (2010). Introduction to Emergency Management. Elsevier.

[31] Dahlhamer, J.M., D'Souza, M.J. (1997). Determinants of business disaster preparedness in two US metropolitan areas. International Journal of Mass Emergencies and Disasters, 15(2): 265-281.

[32] Caponigro, J.R. (2000). The Crisis Counselor: A Stepby-Step Guide to Managing a Business Crisis. McGrawHill Companies.

[33] Pearson, C.M., Mitroff, I.I. (1993). From crisis prone to crisis prepared: A framework for crisis management. Academy of Management Perspectives, 7(1): 48-59. https://doi.org/10.2307/4165107

[34] Drabek, T.E. (1994). Risk perceptions of tourist business managers. Environmental Professional, 16(4): 327-341.

[35] Meheux, K., Parker, E. (2006). Tourist sector perceptions of natural hazards in Vanuatu and the implications for a small island developing state. Tourism Management, 27(1):

69-85. https://doi.org/10.1016/j.tourman.2004.07.009

[36] Webb, G.R., Tierney, K.J., Dahlhamer, J.M. (2002). Predicting long-term business recovery from disaster: A comparison of the Loma Prieta earthquake and Hurricane Andrew. Global Environmental Change Part B: Environmental Hazards, 4(2): 45-58. https://doi.org/10.1016/s1464-2867(03)00005-6

[37] Cronstedt, M. (2002). Prevention, preparedness, response, recovery-an outdated concept? Australian Journal of Emergency Management, 17(2): 10-13.

[38] Mohamed Shaluf, I. (2008). Technological disaster stages and management. Disaster Prevention and Management: An International Journal, 17(1): 114-126. https://doi.org/10.1108/09653560810855928

[39] Richardson, B. (1994). Socio-technical disasters: Profile and prevalence. Disaster Prevention and Management: An International Journal, 3(4): 41-69. https://doi.org/10.1108/09653569410076766

[40] Sutton, J., Tierney, K. (2006). Disaster preparedness: Concepts, guidance, and research, University of Colorado Natural Hazards Center, Institute of Behavioral Science.

[41] Gillespie, D.F., Streeter, C.L. (1987). Conceptualizating and measuring disaster preparedness. International Journal of Mass Emergencies and Disasters, 5(2): 155176.

[42] Ingham, V., Redshaw, S. (2017). Connecting community organisations for disaster preparedness. International Journal of Safety and Security Engineering, 7(1): 52-64. https://doi.org/10.2495/SAFE-V7-N1-52-64 
[43] Fink, S., Association, A.M. (1986). Crisis management: Planning for the inevitable, Amacom.

[44] Litvin, S.W., Goldsmith, R.E., Pan, B. (2008). Electronic word-of-mouth in hospitality and tourism management Tourism Management, 29(3): 458-468. https://doi.org/10.1016/j.tourman.2007.05.011
[45] Gruman, J.A., Chhinzer, N., Smith, G.W. (2011). An exploratory study of the level of disaster preparedness in the Canadian hospitality industry. International Journal of Hospitality \& Tourism Administration, 12(1): 43-59. https://doi.org/10.1080/15256480.2011.540980 